\title{
Management of Acute Subdural Hematomas from Aneurysmal Rupture
}

\author{
Bryce Weir, Terence Myles, Moe Kahn, Falah Maroun, David Malloy, Brien Benoit, Michael \\ McDermott, Douglas Cochrane, Gerard Mohr, Gary Ferguson, Felix Durity
}

\begin{abstract}
Subdural hematomas (SDH) from ruptured aneurysm (RA) are much less common than intracerebral (ICH) hematomas or subarachnoid (SAH) or intraventricular hemorrhage (IVH). With computerized tomography, preoperative diagnosis is now made more often. The authors have collected 18 such cases from a review of 897 cases of RA admitted to eleven medical centers in 1980 and 1981. Nine (50\%) of these patients died prior to discharge from hospital. Four (22\%) had surgery and died postoperatively and $9(50 \%)$ were operated upon and survived. Thirteen $(72 \%)$ of the patients showed anisocoria, decreased consciousness and unilateral weakness prior to surgery. Eight (89\%) of the fatalities had shown preoperative herniation as opposed to only $5(56 \%)$ of the survivors. The overall incidence of delayed ischemia due to vasospasm was $11 \%$ ( 2 cases). Those who died had greater midline shift and larger SDH on the admission CT scan. Sixteen (89\%) of these patients were female. Thirteen $(72 \%)$ had ruptured aneurysms on the internal carotid artery. All of these hematomas were unilateral and uniformly hyperdense, and the convexity hematomas were crescentic in shape. Seventeen (94\%) had evidence of blood in locations other than the subdural space. If the patient is potentially salvageable and has a midline shift, the SDH should probably be evacuated immediately and the aneurysm clipped at the same operation since the development of a tentorial herniation has such an adverse effect on outcome.
\end{abstract}

RÉSUMÉ: A la suite de la rupture d'un anévrysme, l'hématome sous-dural est beaucoup moins fréquent que l'hématome intracérébral ou l'hémorragie sous-arachnoïdienne. La tomodensitométrie en permet plus fréquemment le diagnostic pré-opératoire. Le auteurs ont colligé dix-huit de ces cas après révision de 897 cas d'anévrysmes rupturés admis dans onze centres médicaux en 1980 et 1981. Neuf $(50 \%)$ de ces patients décédèrent avant leur congé de l'hôpital. Quatre $(22 \%)$ avaient été traités chirurgicalement et moururent dans la période post-opératoire. Neuf $(50 \%)$ furent opérés et survécurent. Treize $(72 \%)$ des patients présentèrent une anisocorie, une diminution de l'état de conscience et une faiblesse unilatérale avant la chirurgie. Chez huit (89\%) de ces patients décédés, on avait trouvé une engagement cérébral, alors que ceci se présenta seulement dans cinq (56\%) des survivants. L'incidence globale de l'ischémie tardive secondaire au vasospasme fut de $11 \%$ ( 2 cas). Ceux qui moururent avaient un plus grand déplacement de la ligne médiane et un HSD plus volumineux sur la tomodensitométrie à l'admission. Seize (89\%) de ces patients étaient des femmes. Treize (72\%) étaient porteurs d'un anévrysme rupturé de la carotide interne. Tous ces hématomes étaient unilatéraux et d'une hyperdensité homogène et les hématomes de la convexité avaient une forme de croissant. Chex dix-sept $(94 \%)$, on décela la présence de sang dans d'autres sites que l'espace sous-dural. Si le patient est potentiellement récupérable et a un déplacement de la ligne médiane, l'HSD devrait probablement être évacué immédiatement et l'anévrysme exclu par clip au cours de la même intervention puisque l'engagement trans-tentoriel a un effet tellement défavorable sur le résultat.

Can. J. Neurol. Sci. 1984; 11:371-376

Intracerebral hematomas and intraventricular hemorrhage from ruptured aneurysm (RA) are relatively common (Benoit, 1982; Mohr, 1983; Wheelock, 1983). On the other hand, acute subdural hematomas (SDH) are rare. Most reviews on this subject (Ambrosio, 1968; Barton, 1982; Bassett, 1952; Boop, 1961; Clarke, 1953; Golden, 1963) date from the era prior to CT scanning and were not directed at surgical aspects.

\section{Clinical Material and Methods}

\section{Patient Population}

We studied the medical records of 897 patients with aneurysm rupture who were admitted to 11 hospitals during the years 1980 and 1981. Eighteen of these patients had associated acute subdural hematomas. To be included in the study, a patient must have

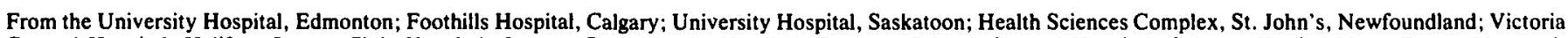
General Hospital, Halifax; Ottawa Civic Hospital, Ottawa; St. Michael's Hospital, Toronto; Calgary General Hospital, Calgary; Hopital Notre Dame, Montreal; University Hospital, London; Vancouver General Hospital, Vancouver.

Received November 10, 1983. Accepted in revised form March 21, 1984.

Reprint requests to: Bryce Weir, M.D., Division of Neurosurgery, 11-102 Clinical Sciences Building, University of Alberta, Edmonton, Alberta, Canada T6G 2 G3. 
had an aneurysm proved by angiography, surgery, or autopsy. A SDH must have been demonstrated, but it was not necessary for the patient to have been operated upon.

\section{Computerized Tomographic Measurement and Angiography}

Actual measurements of SDH were made from CT scans and ratios calculated to allow for differences in magnification. The ratios of the maximum width and length of SDH to the brain width were calculated. The number of $1 \mathrm{~cm}$ cuts in which the SDH was seen were noted. These three numbers were then multiplied by an arbitrary constant (330) to produce an estimate of the size of the SDH in arbitrary units. The principal location of the SDH was classified as frontal, temporal, parietal, occipital or posterior fossa. It was identified as unilateral or bilateral. The midline shift was estimated as a percentage of brain width. The aneurysm was described as arising from the internal carotid, anterior cerebral or middle cerebral artery.

\section{Patient Grading}

The patient's clinical condition was graded as follows: $1=$ asymptomatic; 2 = headache, stiff neck, may be drowsy; $3=$ significant decrease in consciousness, may have mild focal deficit; 4 = decrease in consciousness and major focal deficit; 5 = failing vital signs, pupillary abnormalities, apparently moribund. The clinical grade at admission, at surgery and at discharge was determined. The date of hemorrhage was designated as day $\mathbf{0}$ and the time of admission, surgery and discharge or death were calculated accordingly. A "yes-no" judgment as to the development of a delayed ischemic deterioration attributable to vasospasm (ID-VSP) was made. If patients showed anisocoria, decreased consciousness and unilateral weakness, they were diagnosed as having had a herniation. Discharge destination was indicated as home, rehabilitation facility, chronic care facility (nursing home or auxiliary hospital) or death.

\section{Statistical Analysis}

Figures are given as means. Descriptive statistics and frequencies were categorized by "dead" versus "alive". A discriminate analysis was used to force variables in to predict "live" or "dead" status.

\section{RESULTS}

The general features of the total series of eighteen cases are presented in column 1 of Table 1.

\section{Mortality}

Nine $(50 \%)$ of the patients died. Mortality rate was $100 \%$ for the nonoperative cases and $31 \%$ for the operative cases.

\section{Morbidity}

Three (17\%) of the total number of patients were discharged home but only $2(11 \%)$ were considered to be normal. A further 3 were considered to have a rehabilitation potential and were

Table 1: Data on 18 Patients With Subdural Hematomas Due to Ruptured Aneurysms

\begin{tabular}{|c|c|c|c|}
\hline Parameters & Total Series & Survivors & Deaths \\
\hline Diastolic blood pressure (mmHg) & 90 & 89 & 91 \\
\hline \multicolumn{4}{|l|}{ Clinical grade } \\
\hline On admission & 4 & 4 & 4 \\
\hline At evacuation SDH & 4 & 3 & 4 \\
\hline$\%$ ID-VSP & $11 \%$ & $22 \%$ & $0 \%$ \\
\hline Size of midline shift (\%) & 9 & 6 & 12 \\
\hline Size of SDH & 148 & 63 & 173 \\
\hline \multicolumn{4}{|l|}{ Site of aneurysm } \\
\hline $\mathrm{MCA}$ & $22 \%$ & $0 \%$ & $44 \%$ \\
\hline $\mathrm{ACA}$ & $6 \%$ & $0 \%$ & $11 \%$ \\
\hline ICA & $72 \%$ & $100 \%$ & $44 \%$ \\
\hline$\geqslant 13$ days & $17 \%$ & $33 \%$ & $0 \%$ \\
\hline \multicolumn{4}{|l|}{ Interval to clipping } \\
\hline Not clipped & $29 \%$ & $0 \%$ & $56 \%$ \\
\hline 0 or 1 days & $28 \%$ & $22 \%$ & $33 \%$ \\
\hline $2-12$ days & $22 \%$ & $33 \%$ & $11 \%$ \\
\hline$\geqslant 13$ days & $22 \%$ & $44 \%$ & $0 \%$ \\
\hline Days in hospital & 43 & 59 & 6 \\
\hline Total cases & 18 & 9 & 9 \\
\hline
\end{tabular}

$\mathbf{F}=$ female; $\mathbf{M}=$ male

$\mathrm{MCA}=$ middle cerebral artery; $\mathrm{ACA}=$ anterior cerebral artery; $\mathrm{ICA}=$ internal carotid artery; $\mathrm{SDH}=$ subdural hematoma; ID-VSP $=$ ischemic deterioration due to vasospasm. Size of SDH is in arbitrary units. 
discharged from the neurosurgical service to such a facility. Two (11\%) had major neurologic deficits necessitating discharge to chronic care facilities.

\section{Relative Importance of Factors for Survival}

A comparison of columns 2 and 3 in Table 1 demonstrates no significant difference in admission blood pressures or age for the patients who survived or subsequently died. The patients who died had higher grades on admission and were operated upon earlier, confirming that they were deteriorating faster than those who ultimately survived. The patients who died had greater midline shifts, larger hematomas and a higher percentage of preoperative herniation. Midline shift was the most important predictor of "live" or "dead" status; the next most important was herniation preoperatively.

\section{CT Findings}

Examples of CT scans showing SDH from RA are shown in Figure 1. All these patients showed unilateral, uniformly hyperdense SDH of highly variable thickness. The extent of the midline shift sometimes appeared disproportionate to the relative size of the SDH. All but one of these patients showed blood at other sites in addition to the subdural space. The more sites that were involved, the worse the outcome. The only two patients who showed IVH in addition to SDH both died. Eleven (61\%) of the patients had associated ICH. The overall mortality in this group was 7 (64\%). These findings are summarized in Table 2.

\begin{tabular}{lccc} 
Table 2: Outcome by Type of Bleeding Noted on Initial CT Scan \\
\hline \hline & Home & $\begin{array}{c}\text { Rehabili- } \\
\text { tation }\end{array}$ & $\begin{array}{c}\text { Chronic } \\
\text { Hospital } \\
\text { or Death }\end{array}$ \\
\hline SDH & $n$ & $n$ & $n$ \\
SDH + SAH & 1 & 0 & 0 \\
SDH + ICH & 0 & 2 & 4 \\
SDH + SAH + ICH & 1 & 1 & 0 \\
SDH + ICH + IVH & 1 & 1 & 5 \\
SDH + SAH + ICH + IVH & 0 & 0 & 1 \\
\hline
\end{tabular}

$\mathrm{n}=$ number of cases

SDH = subdural hematoma; $\mathrm{SAH}=$ subarachnoid hemorrhage

$\mathrm{ICH}=$ intracerebral hematoma; IVH = intraventricular hemorrhage

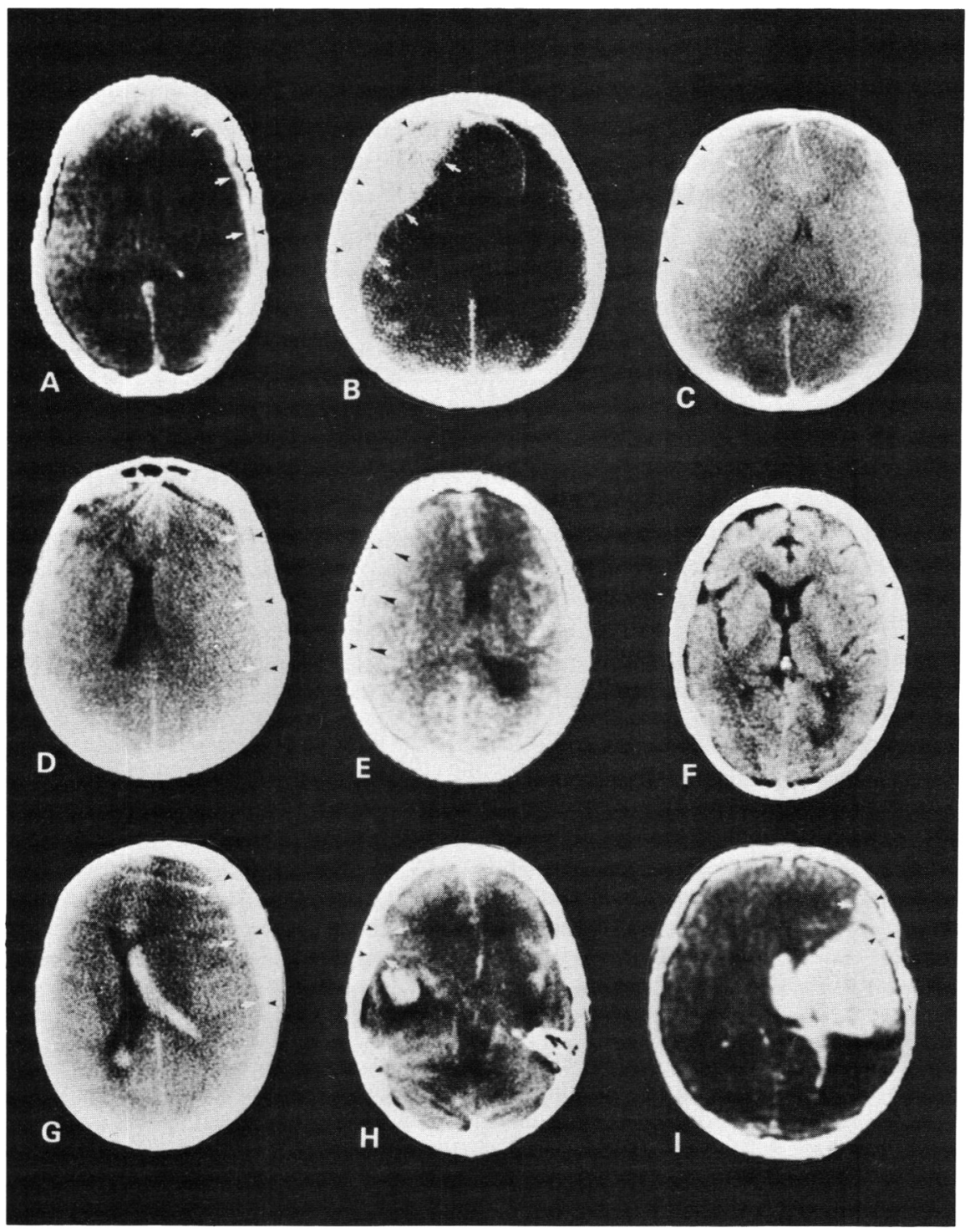

Figure I - Examples of the varied CT appear. ance of subdural hematoma from ruptured aneurysm. Cases A-F had no evidence of intracerebral or intraventricular hemorrhage. Case $B$ had the largest SDH recorded - the patient died rapidly. Case $G$ had a very significant midline shift although the SDH itself was not very large. This patient died as did Case I who also hadIVH and. in addition. a massive ICH. Cases $H$ and I both showed a triangular SDH over the sylvian fissure in association with temporal ICH. 


\section{Ischemic Deterioration Attributed to Vasospasm (ID-VSP)}

The nine patients who died did so on an average of six days following their admission which was day 0 in all but one case. None of them showed ID-VSP. Of the 9 survivors, 2 (22\%) showed a delayed deterioration attributed to ID-VSP.

\section{Discharge Destination}

Figure 2 illustrates the outcome with respect to the initial neurologic grade and the occurrence of preoperative herniation. A poor grade and the occurrence of herniation obviously had an adverse effect.

\section{Type of Surgery}

All of the fatal cases were admitted on day 0 whereas only 6 (67\%) of the survivors were. Only $6(67 \%)$ of the fatal cases survived long enough to have evacuation of the SDH performed whereas all the survivors had clots evacuated. Eight $(89 \%)$ of the survivors had clipping of their aneurysms carried out at the same time as evacuation of the SDH. Only $4(44 \%)$ of the fatalities had the aneurysm clipped.

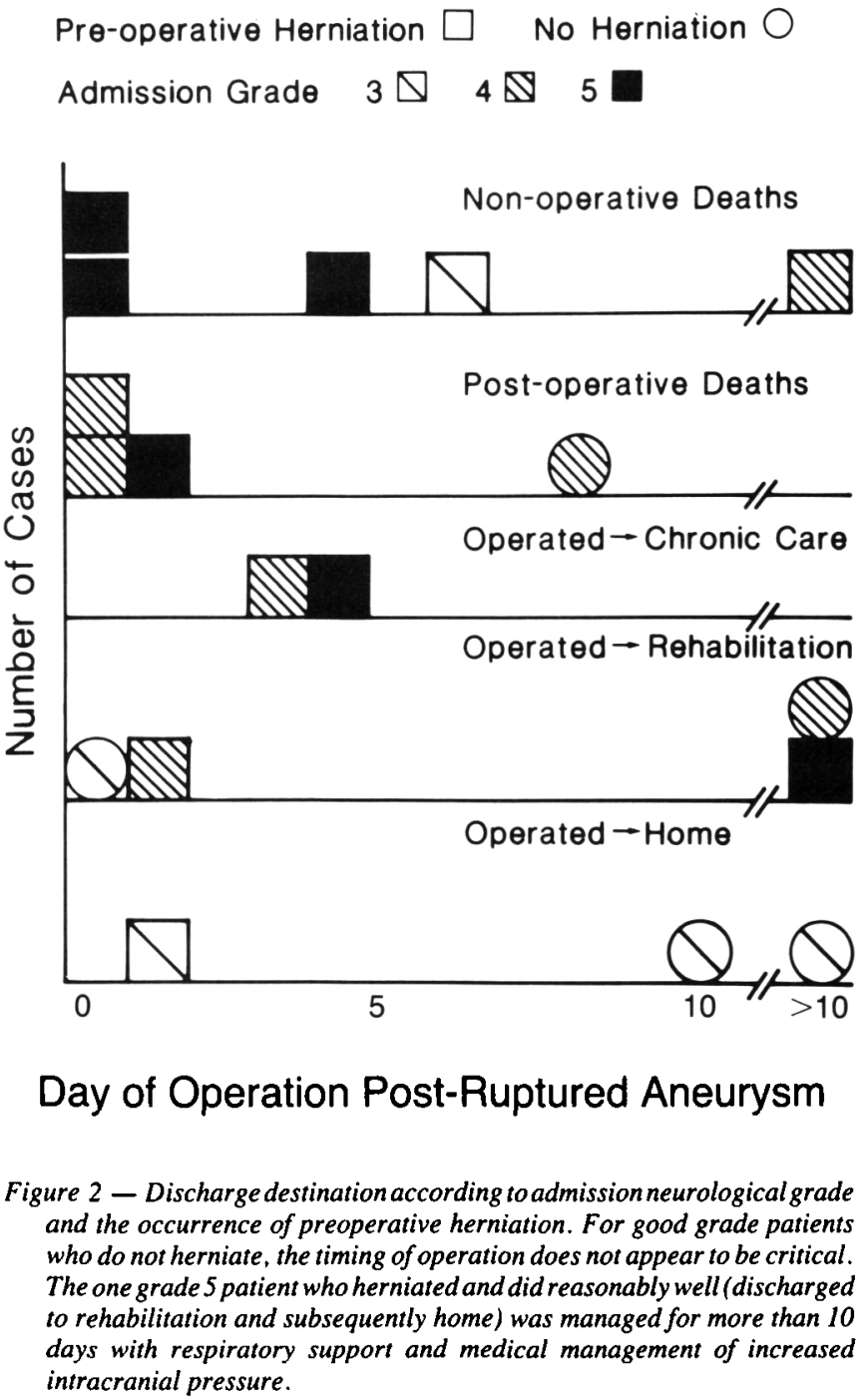

\section{Timing of Surgery}

The three patients discharged home were operated on an average of 12 days post-RA. For the patients discharged to a rehabilitation institute, the average day of surgery was 6 . Of those with poor results (chronic hospital or dead), the average time of surgery was 4 days. The average grade of the patients who were discharged home was 3 on admission and 3 at surgery. For those ending up in a rehabilitation facility, the average grade on admission was 4 and 3 at surgery. For the patients who ultimately had a poor result, the admission grade was 4 and at surgery it was 4 . For the 3 patients who went home, 1 got worse waiting for surgery and 1 got better. For those going to a rehabilitation institute, 2 improved while waiting and none worsened. For the 11 poor results, 3 got better, 3 got worse and 5 showed no change by the time of surgery. Overall it seems that the number of patients who worsened was about the same as the number who improved during the waiting interval.

\section{Discussion}

The rarity of SDH as a complication of RA has been a hindrance to the acquisition of reliable clinical guidelines. Clarke and Walton (1953) published a review of ten such cases gathered between 1920 and 1949. They also reviewed the literature and collected 14 cases from reports between 1895 and 1951. All of their own patients died and there was an $86 \%$ mortality in the cases from the literature. The largest recent series published is that of Barton and Tudor (1982) who identified 11 cases of SDH in 839 RA cases seen over a period of 20 years. Nine of these patients were operated upon. One patient died two days following removal of the subdural clot from re-rupture of the aneurysm. Golden et al. (1953) reported seven SDH cases. Twenty-nine per cent were operated on and survived. There have been recent single case reports from Sachs and Bernat (1978) and Ryan (1979) detailing full recovery following rapid evacuation of SDH in patients who had undergone herniation. Our $50 \%$ mortality rate clearly reflects some improvement on the early series, but indicates that even in the post-CT era, with rapid surgery, some patients have sustained irreversible damage within minutes. Even urgent evacuation of the SDH does not always produce a good result. The $50 \%$ mortality in these 18 patients with SDH compares with a $38 \%$ mortality in 132 cases of $\mathrm{ICH}$ (Wheelock, 1983) and a 64\% mortality in 91 cases of IVH (Mohr, 1983).

Our incidence of $2 \%$ SDH in 897 cases of RA is very close to that reported by Strang (1961) which was $2.8 \%$ in 1414 cases of RA in ten series reported before 1961. Barton and Tudor (1982) had an incidence of $1.3 \%$ in 839 cases.

Possible mechanisms by which an SDH forms following RA include (1) the dome of the aneurysm being adherent to the arachnoid which is torn with the dome to permit direct egress of blood into the subdural space, (2) the stream of blood may rupture through the arachnoid at some distant weak point, (3) the cortex and covering arachnoid may be disrupted by an intracerebral hematoma which then decompresses secondarily into the subdural space. It seems most unlikely that a significant number of aneurysms lie within the subdural space and bleed directly into this site (Barton, 1982; Clarke, 1953).

All aneurysms in this study were considered saccular (berry or "congenital") in origin. Clarke and Walton (1953) reported 
two cases with mycotic aneurysms and King (1960) reported one case. We did not have any cases of traumatic cortical aneurysms but there have been a few such reports recently (Boop, 1961; Miyazaki, 1981; Moriyama, 1978; Sadik, 1963; Tamaki, 1970). Superficial cortical aneurysms are usually due to vessel laceration by bone fragments and are obviously more easily treated than the usual saccular aneurysm on the circle of Willis.

There was a preponderance of females in our series $(89 \%)$. This was also noted by Clarke and Walton (1953) who found $80 \%$ in their personal series.

Fox (1983) reviewed the world literature and found 56 series containing 148 cases, published between 1895 and 1978 . Fortythree per cent were internal carotid, $22 \%$ middle cerebral, $22 \%$ anterior communicating, $4 \%$ vertebrobasilar and $9 \%$ other locations.

Strang (1961) noted the location of the ruptured aneurysm in 60 cases of SDH from the literature and also found an overrepresentation of internal carotid aneurysms $-53 \%$ compared to our $72 \%$. The sites of aneurysm of origin was middle cerebral in $27 \%$, anterior cerebral in $17 \%$, and vertebrobasilar in $3 \%$. Barton and Tudor (1982) found an internal carotid aneurysm in $55 \%$ of cases, middle cerebral in $36 \%$ and anterior cerebral in 9\%. Wright et al. (1965) reported a SDH from a vertebral artery aneurysm and Clarke and Walton (1953) reported a case from the posterior inferior cerebellar artery. Such locations are extremely rare. Another unusual site for SDH is the interhemispheric fissure which was the location for a SDH reported by Fein and Rovit (1970). It had resulted from the rupture of a callosomarginal aneurysm. We cannot comment on the eye findings, but it is of interest that Golden et al. (1953) found subhyaloid hemorrhages in $43 \%$ of their SDH cases from RA whereas in their total series of RA, the frequency of such hemorrhages was only 1.2\%. Barton and Tudor (1982) also noted a high incidence of subhyaloid hemorrhages in their SDH cases $-45 \%$.

Barnett (1969) reviewed a pathological series of 33 SDH due to aneursyms, $30 \%$ were considered to be incidental, $45 \%$ as contributing to death and $24 \%$ as being the direct cause of death. Duration of survival was greater than one week in only $13 \%$ of cases.

Not only can trauma precipitate the formation and subsequent rupture of an aneurysm, but it may be instrumental in causing the rupture of a true saccular aneurysm. Bassett and Lemmen (1952) found a history of significant trauma in three of their five cases of SDH. To differentiate SDH from RA or trauma on a CT scan, the following criteria should be considered. RA produces unilateral, hyperdense SDH which are crescentic in convexity or triangular over the lower sylvian fissure. Traumatic SDH are more likely to be of mixed, iso- or hypodensity, may be bilateral and may be lentiform as well as crescentic. SDH from RA are frequently associated with SAH, ICH or IVH while traumatic ones may show only SDH or show hemorrhagic contusions with further evidence of scalp or bony injury. Direct visualization of the aneurysm may also be obtained of course. If there is no historical evidence of a significant head injury, then angiography should be considered.

Since a CT scan rather than an angiogram is now the initial study for most patients with an intracranial catastrophe, there is a danger that the possible aneurysmal origin of a SDH will be overlooked. There are few reports on the CT appearance of
SDH from RA. A review of 13 articles published between 1976 and 1980 by Eggers et al. (1982) included only three cases with SDH in the 848 cases of RA studied by CT scan. This incidence of approximately $.35 \%$ was almost certainly lower than the incidence of SDH complicating RA. CT studies in three new cases were reported by Eggers et al. (1982), and others have been reported as follows: Sachs and Bernat (1978) - one, Barton and Tudor (1982) - two, and Rengachary and Szymanski (1981) - one. In the two fatal cases of Eggers et al., one had a huge SDH and the other had a SDH associated with an $\mathrm{ICH}$ and an IVH.

The only case to our knowledge in the literature of a bilateral SDH associated with the presence of an aneurysm was that of Kawiak (1978) in a patient who also had an arteriovenous malformation.

Not all CT scans had actual measurement scales so we were unable to calculate actual volumes. Sachs and Sachs (1977) have suggested a formula for this purpose.

Good results have been reported in occasional cases where the aneurysm was not clipped at the time of evacuation of the hematoma. Also, occasional good results in our series followed delayed operation with initial medical management of the patient's intracranial hypertension. The good outcome was more likely due to the good admission grade and infrequency of herniation than delay in surgery. Notwithstanding this, the wisest course of action is probably to clip the aneurysm at time of evacuation of the SDH. The clot removal can easily be carried out through the standard frontotemporal craniotomy. There is no obvious advantage to waiting since as many patients appear to deteriorate as improve. There is also the omnipresent danger of rebleeding and/or brain herniation. Once herniation occurs, the prognosis is poor.

\section{ACKNOWLEDGEMENTS}

We would like to thank our colleagues for the use of their case material and Michael Grace, Ph.D., for statistical advice.

\section{REFERENCES}

Ambrosio A, Profeta G, Maggi G (1968) Intracranial subdural hematomas caused by rupture of cerebral aneurysms. Rass. Int. Clin. Ter. 48: 1469-1479.

Barnett HJM (1969) Some clinical features of intracranial aneurysms. Clin. Neurosurg. 16: 43-71.

Barton E, Tudor J (1982) Subdural haematoma in association with intracranial aneurysm. Neuroradiology 23: 157-160.

Bassett RC, Lemmen LJ (1952) Subdural hematoma associated with bleeding intracranial aneurysm. J. Neurosurg. 9: 443-450.

Benoit BG, Cochrane DD, Durity F, Ferguson GG, Fewer D, Hunter KM, Khan MI, Mohr G, Watts AR, Weir BKA, Wheelock WB (1982) Clinical-radiological correlates in intracerebral hematomas due to aneurysmal rupture. Can. J. Neurol. Sci. 9: 409-414.

Bergstrom K, Hemmingsson A (1973) False cortical aneurysm in subdural haematoma following head injury without fracture. Acta Radiol. (Diagn.) (Stockh.) 14: 657-661.

Boop WC Jr, Chou SN, French LA (1961) Ruptured intracranial aneurysm complicated by subdural hematoma J. Neurosurg. 18: 834-836.

Clarke E, Walton JN (1953) Subdural hematoma complicating intracranial aneurysm and angioma. Brain 76: 378-404.

Eggers FM, Tomsick TA, Lukin RR, Chambers AA (1982) Recognition of subdural hematoma secondary to ruptured aneurysm by computerized tomography. Comput. Radiol. 6: 309-313. 
Fein JM, Rovit RL (1970) Interhemispheric subdural hematoma secondary to hemorrhage from a callosomarginal artery aneurysm. Neuroradiology 1: 183-186.

Fox JL (1983) Intracranial Aneurysms. Volume 1. New York: SpringerVerlag, New York Inc., pp. 199-203.

Golden J, Odom GL, Woodhall B (1953) Subdural hematoma following subarachnoid hemorrhage. Arch. Neurol. Psychiatry 69: 486-489.

Handel SF, Perpetuo FO, Handel CH (1978) Subdural hematomas due to ruptured cerebral aneurysms: Angiographic diagnosis and potential pitfalls for CT. A.J.R. 130: 507-509.

Kawiak W, Stelmasiak Z, Zomaniec J, Nowicka J, Tarach B (1978) Case of arteriovenous hemangioma, aneurysm and subdural hematoma. Neurol. Neurochir. Pol. 12: 503-505.

King AB (1960) Successful surgical treatment of an intracranial mycotic aneurysm complicated by a subdural hematoma. J. Neurosurg. 17: 788-791.

Miyazaki J, Fukushima H, Kamata K, Ishii S (1981) False aneurysm with subdural hematoma and symptomatic vasospasm following head injury. Surg. Neurol. 16: 443-447.

Mohr G, Ferguson G, Khan M, Malloy D, Watts R, Benoit B, Weir B (1983) Intraventricular hemorrhage from ruptured aneurysm. Retrospective analysis of 91 cases. J. Neurosurg. 58: 482-487.

Moriyama T, Tanaka T (1978) A surgical case with traumatic false aneurysm, arteriovenous fistula of the middle meningeal artery, ipsilateral chronic subdural hematoma and contralateral subdural hydroma and non-traumatic vertebrooccipital anastomosis. No Shinkei Geka 6: 1113-1118.

Rengachary SS, Szymanski DC (1981) Subdural hematomas of arterial origin. Neurosurgery 8: 166-171.

Ryan EP (1979) Rupture of intracranial aneurysm causing acute subdural hematoma, intratemporal hematoma and decerebration with survival: Case report. Neurosurgery 5: 698-700.
Sachs E Jr, Bernat JL (1978) Recovery from acute subdural hematoma and uncal herniation due to ruptured intracranial aneurysm. Neurosurgery 3: 66-67.

Sachs J, Sachs E Jr (1977) A simple formula for calculating the volume of subdural hematomas. Neurosurgery 1: 60-61.

Sadik AR, Adachi M, Ransohoff J (1963) Rupture of an intracranial aneurysm within the subdural space - in association with trauma. A case report. J. Neurosurg. 20: 609-612.

Someda K, Yasui N, Moriwaki Y, Kawamura Y, Matsumura H (1975) Extravasation of contrast material into subdural space from internal carotid aneurysm during angiography. Case report. J. Neurosurg. 42: 473-477.

Sonobe M, Takahashi S, Nagamine Y, Ohara H, Shibazaki S, Nemoto H (1981) Chronic subdural hematoma associated with intracranial aneurysm. No Shinkei Geka 9: 741-745.

Strang RR, Tovi D, Hugosson R (1961) Subdural hematomas resulting from the rupture of intracranial arterial aneurysms. Acta Chir. Scand. 121: 345-350.

Tamaki N, Yanashita H (1970) Traumatic false aneurysm of the middle meningeal artery: Possible mode of aneurysm formation and its clinical significance. Brain Nerve (Tokyo) 22: 489-494.

Wheelock B, Weir B, Watts R, Mohr G, Khan M, Hunter M, Fewer D, Ferguson G, Durity F, Cochrane D, Benoit B (1983) Timing of surgery for intracerebral hematomas due to aneurysm rupture. $J$. Neurosurg. 58: 476-481.

Wright JR, Slavin RE, Wagner JA (1965) Intracranial aneurysm as a cause of subdural hematoma of the posterior fossa. J. Neurosurg. 22: 86-89. 